\title{
OPEN EDUCATION RESOURCE ON HEAT TRANSFER: AN EFFECTIVE ICT TOOL FOR FACULTY AND STUDENTS
}

\author{
A.Padmaja ${ }^{1}$, Md.Sikindar Baba ${ }^{2}$ \\ ${ }^{1}$ VidyaJyothi Institute of Technology, Hyderabad, Telangana, India \\ ${ }^{2}$ Mechanical Engineering,Anurag Group of Institutions, Hyderabad, Telangana, India \\ ${ }^{1}$ principalvjit@vjit.ac.in , \\ ${ }^{2}$ sikindar@cvsr.ac.in
}

\begin{abstract}
The problem of education is a very important one and occupies an increasingly wider register among educational specialists, who see these changes directly related to current generations of students. Open Educational Resource(OER) is gaining popularity in the recent times. OER are educational resources such as texts, images, videos, assignments, courses, etc. which are freely accessible to anyone and can be used to teach and learn.It also represents an opportunity to have one's own materials enhanced. By allowing material to be modified by other faculty around the world, an OER creator has the chance to see material used in ways never imagined. OER is important because it provides affordable material to students, allows faculty to enhance their own work, and provides faculty with content for classes. Open educational resources help students be ready for learning on day one. Keeping in view the importance of OER and the beneficial advantages it has for both faculty and students, this paper is an attempt in this direction. OER has been created for Heat transfer course on let's learn some basics on Heat Transfer and Heat Exchangers. The outcomes of the OER are students can know the basics of Heat transfer and modes of heat transfer , understand heat Exchangers and their effectiveness and applications. This OER addresses the blooms higher levels in solving the problems. Another important aspect is students are able to apply the knowledge in solving the problems on overall Heat Transfer Coefficient \& effectiveness of heat exchangers. To support the students, to enhance the skills and share their work, an Open Education Resource(OER) with name OER Word Press blog was created. This platform helps students and teaching community associated with the heat transfer course. This resource is licenced under CC-BY-SA Ver 4.0 You are free to use, distribute and modify it for commercial purposes, provided you acknowledge the source and share alike.
\end{abstract}

Key words : Heat Transfer, Conduction, Convection ,Radiation,Flipped Classroom, MOODLE, , Effectiveness, heat exchangers, Boilers Condensers, LMTD, Basic modes of Heat transfer

\begin{abstract}
Introduction
In 1994 Wayne Hodgins coined the term "learning object," and this term quickly entered the vernacular of educators and instructional designers. One role of learning objects in the history of OER is its popularization of the idea that digital materials can be designed and produced in such a manner as to be reused easily in a variety of pedagogical situations. ${ }^{1}$

Open Educational Resources are defined as "technologyenabled, open provision of educational resources for consultation, use and adaptation by a community of users for non-commercial purposes." They are typically made freely available over the Web or the Internet. Their principal use is by teachers and educational institutions support course development, but they can also be used directly by students. Open Educational Resources include learning objects such as lecture material, references and readings, simulations, experiments and demonstrations, as well as syllabi, curricula and teachers' guides.
\end{abstract}

As digital learning materials slowly replace traditional print-based resources, open educational resources, or OERs, are gaining popularity in a number of schools and districts. OERs include any type of learning materials that are released into public domain under an open license, and teachers are free to use, copy, share and amend them to suit the needs of their students.

On the internet, the world of open educational resources is nearly endless - and it can be overwhelming to educators in search of standardsaligned lesson plans that fit their specific needs.

This paper describes the OER designed on heat transfer course, and the steps involved in designing the OER and its effectiveness

\footnotetext{
About the OER:

The open education resource is a collection of MOODLE Lesson activities that are useful as out-of-class activity while flipping the classroom.

There are 3 lessons as part of this OER, and each deals with an aspect related to
} 


\section{Lesson 1}

1.Explain the theory behind different modes of Heat Transfer

2.Fouriers law of conduction/derive the equation for any surface

3.Heat Transfer through conduction and sample problem in a furnace to understand the concept

\section{Lesson 2}

1. Heat Exchangers and applications of Heat Exchangers

2. Overall Heat transfer coefficient in a heat exchanger

Lesson 3

1. Understand the effectiveness of different types of heat exchangers

2. Calculate NTU and minimum heat capacity and calculate effectiveness from the graph

3. Understand the effectiveness of Heat Exchanger with phase exchangers (Boilers/Condensers)

1.Screen cast https://vimeo.com/168083145

2.Annalyzing the effectiveness of different types of heat exchangers

3.Evaluation of effectiveness and LMTD and their composition OER is downloadable from: wordpress web page:padmajaweb.wordpress.com

\section{Learning Objectives}

After using this OER, learner will be able to:

\section{Lesson 1}

- Explain the theory behind different modes of heat transfer

- Fourier's law of conduction/derive the equation for any surface

- Heat transfer through conduction and sample Lesson 2 problem in a furnace to understand the concept

- To understand heat Exchangers \& applications of heat exchangers

- Overall Heat Transfer Coefficient for a wall or Heat Exchanger

\section{Lesson 3}

- Understand the effectiveness of different types of heat exchangers

- Calculate NTU and Minimum heat capacity and calculate effectiveness from the appropriate graph

- Understand the effectiveness of Heat exchanger with phase change (Boilers/condensers)

- Analyzing the effectiveness of different types of heat exchanger
- Evaluation of effectiveness and LMTD and their comparison

\section{Helpful Documentation for Tool Use}

1. For design \& development of lesson activity in MOODLE(moodlecloud.com)

2. Screen Casts/vimeo/PPTS

3. Word Press

\section{Section 2: Design Decisions}

Nature of Decisions taken

The design decisions involved in the creation of this OER were of broadly three types:

1. Content Decisions

2. Pedagogic Decisions

3. Technology Decisions

\section{Content Decisions}

The content decisions related to:

1. Lesson wise : Areas to be covered were identified-Decided on Heat Transfer Basics \& Heat Exchangers ,Its Effectiveness of different types of heat exchangers, with phase change and LMTD

2. Decided on the Videos /PPTS to be provided for Out of class activity and in class activity

3. NPTEL \& Other resources on the topic ,Question bank

\section{Pedagogic Decisions}

Typically, in a flipped classroom strategy, there are two segments - Out-of-class segment and In-Class segment. Decisions were taken on the material to be provided for the out of class activity. (Videos/PPTS) to understand/ to get an overview on the topic to be covered in the class. In terms of concept marking the pedagogic decisions that were taken for the Out-of-class segment related to:

a. Cognitive Levels of Questions to be asked along with the resources - Mostly Recall Applying level question for out of class and Create Level question for In-class activity covering the Blooms higher level :Analyze,Create \& Evaluate

b. Assessment Strategies: Through assignments to meet the learning outcomes

Out of class activity: Giving questions based on the videos and ask them to submit before coming to class. (Blooms Level : Understand \& Recall)

1. Lesson 1 : Screencast Video : http://screencast-omatic.com/watch/cDhTFIihuJ 
2. Basics PPT :

Conduction:Convection:Radiation with simple questions \& Answers

3. Lesson2 Screencast Video : http://screencast-omatic.com/watch/cDhTbkihtI

4. Lesson 3 : Screen cast video :https://vimeo.com/168082481

5. Screen cast https://vimeo.com/168083145

\begin{tabular}{|l|l|}
\hline Step:1 & $\begin{array}{l}\text { Students are divided into a group of } 4 \text { or 5. The } \\
\text { group should be diverse in terms of gender, } \\
\text { ability and skill. }\end{array}$ \\
\hline Step:2 & $\begin{array}{l}\text { The days lesson is divided into } 4-5 \text { segments } \\
\text { (one for each member) }\end{array}$ \\
\hline Step:3 & $\begin{array}{l}\text { Each student is assigned one segment to learn. } \\
\text { Each student should only have direct access to } \\
\text { their own segment. }\end{array}$ \\
\hline Step:4 & $\begin{array}{l}\text { Students should be given time to read their } \\
\text { segment to become familiar with it. }\end{array}$ \\
\hline Step:5 & $\begin{array}{l}\text { Temporary experts groups should be formed in } \\
\text { which one student from each JIGSAW group } \\
\text { joins other students assigned to the same } \\
\text { segment. Students in this expert group should be } \\
\text { given time to discuss the points of their segment }\end{array}$ \\
\hline Step:6 & $\begin{array}{l}\text { Students come back to their JIGSAW group and } \\
\text { present their segment to the group }\end{array}$ \\
\hline
\end{tabular}

In Class activity: (Blooms level: Analyze, Create \& Evaluate)

Lesson 1: Active learning Strategy: Problem Solving

Learning Objectives

1. Students are able to derive and apply Fourier's law of conduction/derive the equation for any surface

2. Students will be able to solve the problems on heat transfer through conduction and apply their knowledge about heat conduction to solve new problems

\section{Active learning strategy: Problem Solving}

- Presenting students with a problem to be solved in class

- $\quad$ Providing some structure or guidance towards solving the problem

- At the end of the problem solving,

- Reaching a final outcome or solution with reference to learning objectives

Lesson 3: Active learning strategy : JIGSAW
1. Analyzing the effectiveness of different types of heat exchanger

2. Evaluation of effectiveness and LMTD and their comparison

The topic is divided into 4 subtopics and the teacher divides the students as per the following:

Out of class activity : Giving questions based on the videos and ask them to submit before coming to class. (Blooms Level : Understand \& Recall)

6. Lesson 1 : Screencast Video : http://screencast-omatic.com/watch/cDhTFIihuJ

7. Basics PPT : Conduction:Convection:Radiation with simple questions \& Answers

8. Lesson 2 Screencast Video : http://screencast-omatic.com/watch/cDhTbkihtI

9. Lesson 3 : Screen cast video :https://vimeo.com/168082481

10. Screen cast https://vimeo.com/168083145

The topic is divided into 4 subtopics and the teacher divides the students as per the following:

\section{Technology Decisions}

While developing the Out-of-Class and In-class activities, the major technology decisions taken were:

a. Tool to be used for creating screencast http://screencast-o-matic.com/

b. Vimeo

c. MOODLE Lesson Activity for setting up Outof-Class segment as it allowed guided selflearning through moodlecloud.com

Section 3: OER Description

\section{Active OER}

For checking the active OER, you may access the Guest Course - https://padmajavjit.moodlecloud.com/

Lesson Settings

Screenshots 1-3 shows the general settings of a Lesson. This is same for all the lessons. If there are variations, then they are duly noted under each description.

Screenshot 1: General and Appearance setting in MOODLE

Learning Objectives 


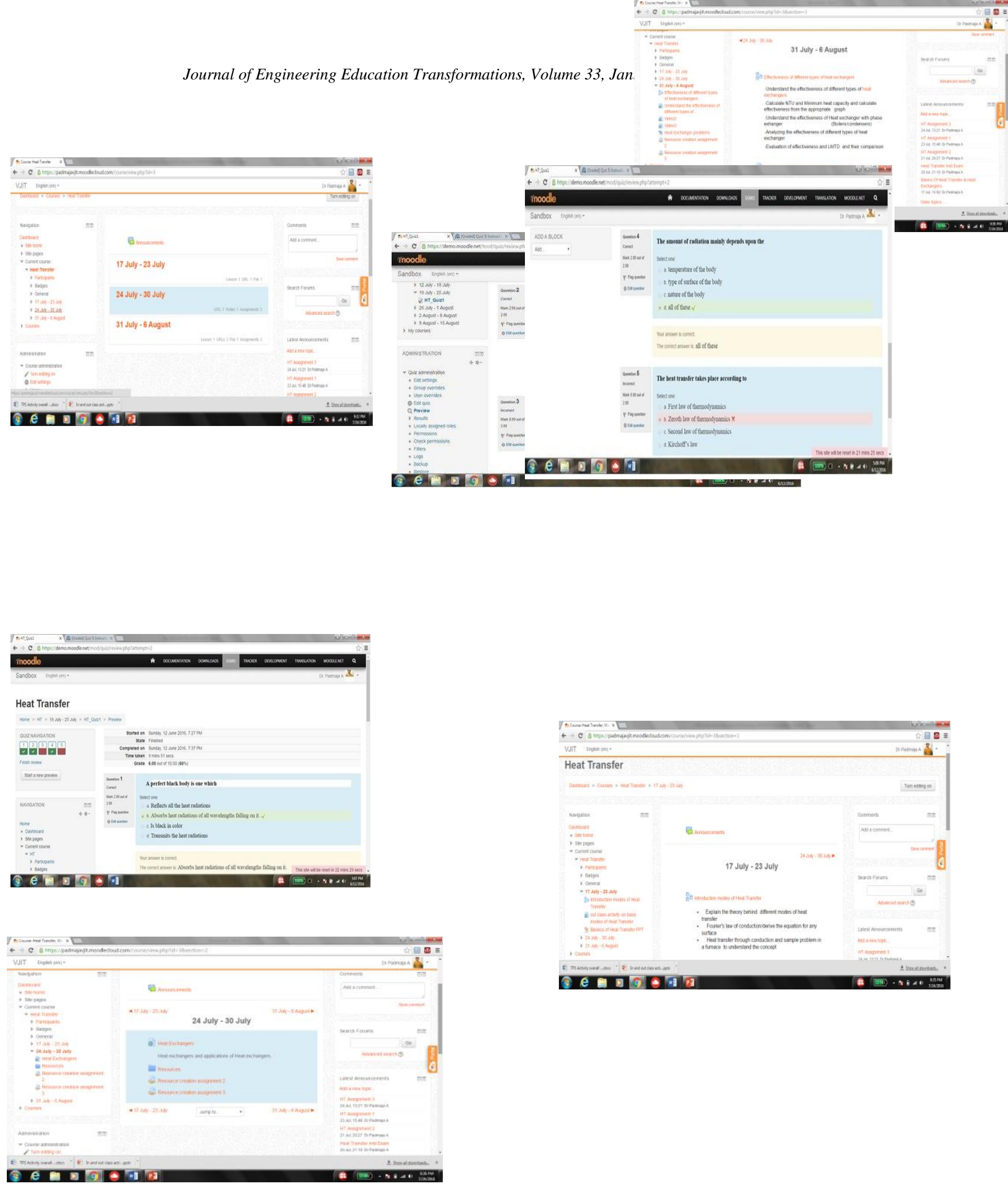



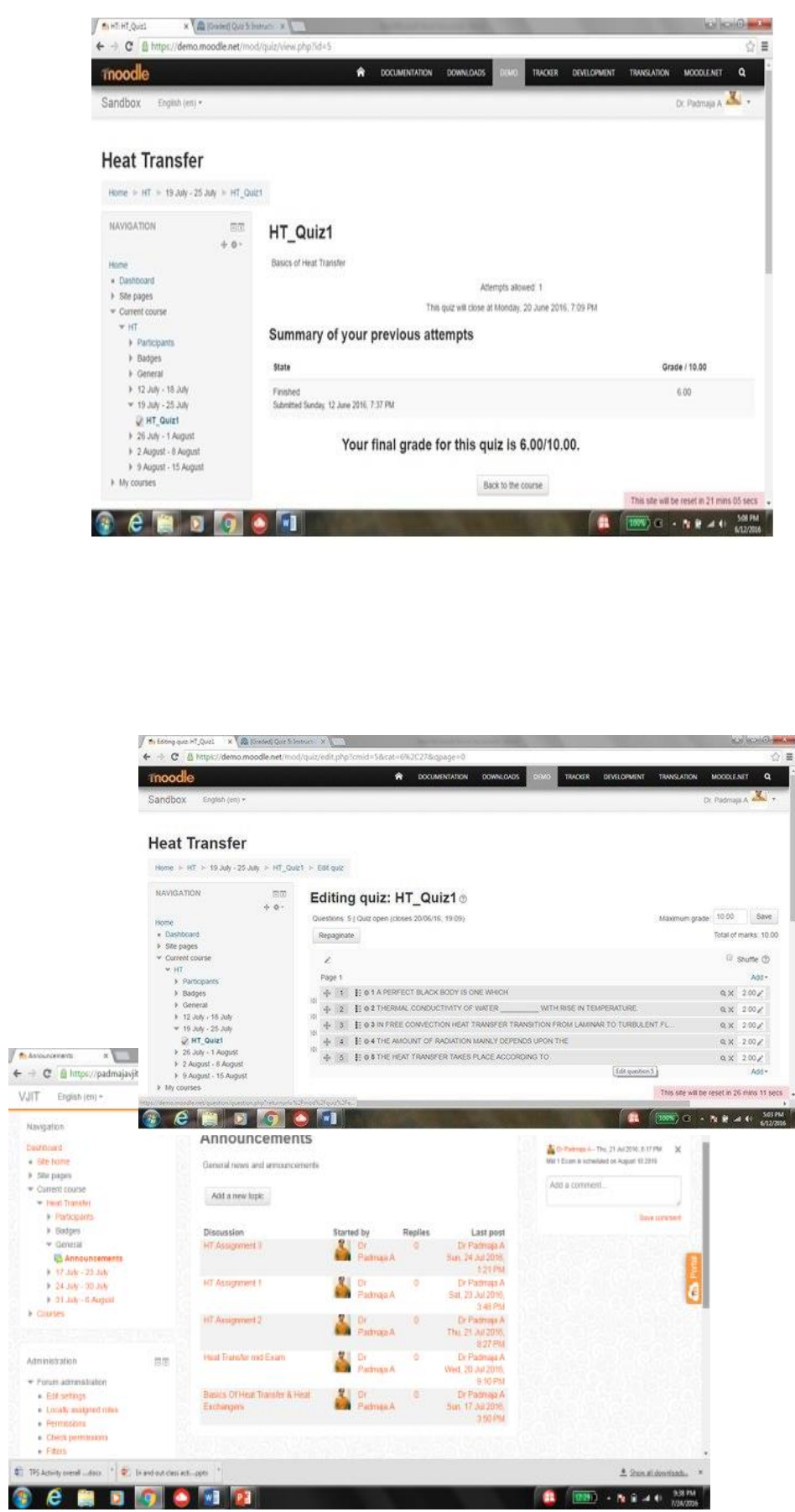

For using this OER, please ensure that you have admin permission in your MOODLE course (needed for importing activities). Else ask your administrator to restore this backup in your course.

Step 1: Download the (OER) from https://padmajaweb.wordpress.com/

Step 2: Go to the https://padmajavjit.moodlecloud.com/.

In the Administration section click "Restore"Credentials : User name: guestuser , Password : guestuser1234

Best Practices with Lesson Activity
Here are some of the best practices from our experience on using this Lesson Activity in classroom:

1. Assignments are given every week to track the understanding of the concept

2. Out of class activity \& Inclass activity are planned for the lessons : Keeping in view Blooms levels low for out of class activity and higher levels for in class activity

3. Learning objectives and outcomes are clearly stated and assessment strategies are clearly mentioned in the resource creation ppts.

4. Resources : given are sufficient for understanding of concept.NPTEL related videos are also given as resources for the student.

5. Incentives for students who submit the assignments in time (all 3 assignments)

https://screencast-o-matic.com/watch/cDXUbJQ62a

Section 4: Evaluating Effectiveness of OER

The OER effectiveness can be assessed at two levels:

1. At the student level

2. At the consumer level

Effectiveness at the student level

To assess the students assignments are given at every stage.

\section{Effectiveness at consumer level}

OER consumers are typically teachers who want their students to learn concept mapping.

Linking a survey on three main constructs - Ease of Use, Concept Coverage and Concept Complexity, can help in identifying the effectiveness of this OER at consumer level. This has to be done as a followup activity.

\section{Implementing Survey}

Thus, every user who downloads this resource will be asked their email address and as a follow up the survey will be send to their email address.

Survey Questions

\begin{tabular}{|l|l|l|}
\hline Construct & \multicolumn{1}{|c|}{ Question } & \multicolumn{1}{|c|}{ Scale } \\
\hline & $\begin{array}{l}\text { I found it easy to download } \\
\text { the lesson activity }\end{array}$ & \\
\cline { 2 - 3 } & $\begin{array}{l}\text { I found the instructions to } \\
\text { setup the lesson activity } \\
\text { useful in setting the } \\
\text { activity in my course }\end{array}$ & $\begin{array}{l}\text { Strongly } \\
\text { Disagree to }\end{array}$ \\
\hline
\end{tabular}




\begin{tabular}{|l|l|l|}
\hline Ease of Use & $\begin{array}{l}\text { I was able to successfully } \\
\text { create Lesson in my own } \\
\text { Course }\end{array}$ & $\begin{array}{l}\text { Strongly } \\
\text { Agree (5- } \\
\text { point scale) }\end{array}$ \\
\hline $\begin{array}{l}\text { Concept } \\
\text { Coverage }\end{array}$ & $\begin{array}{l}\text { The Lesson covers the } \\
\text { required concepts related } \\
\text { to concept maps that I need } \\
\text { for my course }\end{array}$ & \\
\hline
\end{tabular}

\section{Conclusions}

The benefit of OER to education is more powerful than simply reducing the cost of textbooks, which is often the catch phrase used when describing its value. Using open resources has the power to literally transform teaching and learning in ways that improve both student and faculty engagement. Using open resources in instruction can create the customized and personalized learning that has the promise to open up our classrooms to those students who so need to be freed from its current construct.

OER can engage students in deeper ways as well, with new approaches like one proposed by David Wiley around assigning renewable rather than disposable homework assignments. Students, tasked with homework of value, can learn by retrieving, remixing, and redistributing OER as part of a richer and deeper classroom experience. The proposed designed model described in this paper would definitely results in higher learning capabilities, critical thinking and problem solving which ensues the student for better performance.

\section{Acknowledgement}

Authors gratefully acknowledge IIT Bombay team during the FDP: Use of ICT Education for online and blended learning for teaching flipped classroom strategy.

\section{References}

1. https://iitbombayx.in/c4x/IITBombayX/FDPICT 001x/asset/OER_Submission_Example.pdf

2. Organization for Economic Co-operation and Development Centre for Educational Research and Innovation Expert Meeting on Open Educational Resources David Wiley, Utah State University Center for Open and Sustainable Learning. https://hewlett.org/wpcontent/uploads/2016/08/HistoryofOER.pdf

3. How do you choose an open educational resource?

https://www.educationdive.com/news/how-doyou-choose-an-open-educationalresource/504110/

4. Open Educational resources : Opportunities and Challenges https://www.researchgate.net/publication/235984 502_Open_educational_resources_ Opportunities_and_challenges

5. MATEC Web of Conferences 121, MSE 2017 12006 (2017)

6. The importance of OER online courses in the democratization of education https://blog.eliademy.com/2015/04/23/theimportance-of-oer-online-courses-in-thedemocratization-of-education/\#.W1FxOtIzbIU

7. https://opentextbc.ca/studenttoolkit/chapter/stepone-what-are-oer/

8. The Role of Open Educational Resources in the Student Success Agenda http://www.achievingthedream.org/blog/16081/t he-role-of-open-educational-resources-in-thestudent-success-agenda-huffington-post-blog 